\title{
Synthesis and evaluation of coumarin derivatives against human lung cancer cell lines
}

\author{
K.-G. Weng ${ }^{1}$ and Y.-L. Yuan ${ }^{2}$ \\ ${ }^{1}$ Department of Radiation Oncology, Chongqing Cancer Institute and Hospital and Cancer Center, Chongqing, China \\ ${ }^{2}$ Department of Clinical Laboratory, Chongqing the Seventh People's Hospital, Chongqing, China
}

\begin{abstract}
Series of novel coumarin derivatives [I (a-d) and II (a-d)] were successfully synthesized and their structures were determined based on infrared $1 \mathrm{H}$-nuclear magnetic resonance (NMR), HRMS, and single crystal X-ray crystallography. Additionally, the new synthesized compounds were evaluated to identify the molecular characteristics that contribute to their cytotoxicity, which was tested against SK-LU-1, SPC-A-1 and 95D human lung cancer cell lines, using the MTT assay. The results of this study showed that compounds Ic, Id, Ilc, and Ild exhibited an efficient percentage of inhibition of cell proliferation.
\end{abstract}

Key words: Coumarin; X-ray; Lung cancer

\section{Introduction}

Cancer is the leading cause of death in developed countries and the second leading cause of death in developing countries (1-3). Currently, the traditional therapies of surgery, chemotherapy and radiation play an important role in the systemic treatment of cancer (4-6). However, the treatment outcome is generally poor. Thus, it is very important to find an effective alternative treatment for cancer (7-9).

Coumarins are an important class of compounds of both natural and synthetic origin. Many compounds that contain the coumarin moiety exhibit useful and diverse pharmaceutical and biological activities, and there has been a growing interest in their synthesis (10-12). Some of these coumarin derivatives have been found useful in photochemotherapy, antitumor and anti-HIV therapy, as CNS-stimulants, antibacterial, anticoagulant, antifungal, and antioxidant agents, and as dyes (13-15). Natural, semi-synthetic and synthetic coumarins are useful substances in drug research. Coumarins can be used not only to treat cancer, but also to treat the side effects caused by radiotherapy (16-18). In this paper, series of coumarin derivatives [I $(a-d)$ and II $(a-d)]$ (Figure 1) have been synthesized and their potential antitumor activity was investigated.

\section{Material and Methods}

\section{Apparatus and materials}

To obtain infrared (IR) spectra $\left(400-4000 \mathrm{~cm}^{-1}\right)$, we used a Brucker Equinox-55 spectrophotometer (Bruker,
Germany), to obtain $1 \mathrm{H}$-nuclear magnetic resonance (NMR) spectra we used a Varian Inova-400 spectrometer (Virian USA; at $400 \mathrm{MHz}$ ), and for the Mass spectra, we used a micrOTOF-Q II mass spectrometer (Bruker, Germany). The melting points were taken on a XT-4 micro melting apparatus (Ledon, China), and the thermometer was uncorrected.

Synthesis and characterization of compounds I (a-d) and II (a-d)

Compounds I (a-d) were synthesized according to the methods of a previous report (19). A mixture of aromatic aldehydes $(10 \mathrm{mmol})$ and 4-hydroxycoumarin $(20 \mathrm{mmol})$ was dissolved in $100 \mathrm{~mL}$ of acetic anhydride (Ac2O). A few drops of piperidine were added, and the mixture was stirred for $3 \mathrm{~h}$ at room temperature. After reaction completion, determined by thin-layer chromatography, water was added until precipitation occurred. After filtering the precipitates, they were sequentially washed with icecooled water and ethanol and then dried in a vacuum.

I a. 7H-pyrano[3,2-c;5,6-c']dichromene-6,8-dione: 279$280^{\circ} \mathrm{C}$. IR (KBr pellet cm ${ }^{-1}$ ): 3432, 2844, 1943, 1564, 1108 $\mathrm{cm}^{-1}$. 1H NMR (DMSO-d6, $\delta, \mathrm{ppm}$ ): 7.912-7.960 (m, 2H), 7.562-7.647 (m, 2H), 7.321-7.389 (m, 4H), $3.789(\mathrm{~s}, 1 \mathrm{H})$, $3.680(\mathrm{~s}, 1 \mathrm{H})$. HRMS $(\mathrm{ESI}+)$ : $\mathrm{m} / \mathrm{z}$ : calcd for $\mathrm{C} 19 \mathrm{H} 1005$ : $341.0420[\mathrm{M}+\mathrm{Na}+]$; found: 341.0419 .

I b. 7-(3,4-dimethyl-phenyl)-7H-pyrano[3,2-c;5,6-c']dichromene-6,8-dione: $>300^{\circ} \mathrm{C}$. IR $\left(\mathrm{KBr}\right.$ pellet $\left.\mathrm{cm}^{-1}\right)$ : 3433, 2834, 1870, 1581, $1060 \mathrm{~cm}^{-1}$. 1H NMR (DMSO-d6, $\delta, \mathrm{ppm}$ ):

Correspondence: K.-G. Weng: <kegui.weng666@gmail.com> 


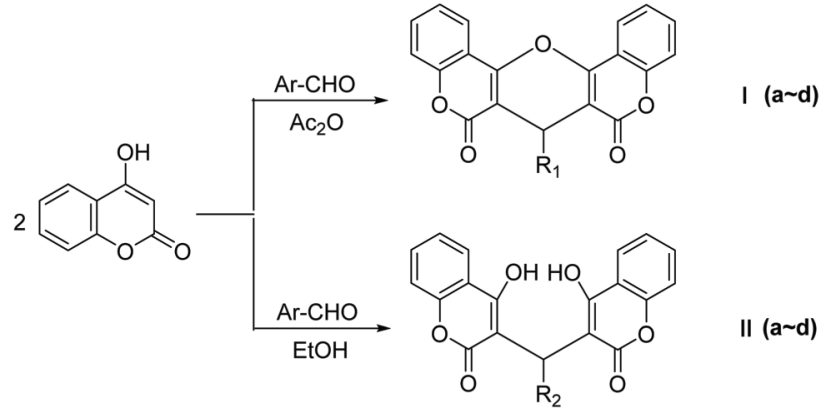

(II)

Figure 1. Synthesis route of compounds I (a-d) and II $(a-d)$ 8.388-8.407(d, 2H), 7.747-7.765(t, 2H), 7.497-7.567(m, $4 \mathrm{H}), 7.127(\mathrm{~s}, 1 \mathrm{H}), 7.066-7.085(\mathrm{~d}, 1 \mathrm{H}), 7.009-7.029(\mathrm{~d}, 1 \mathrm{H})$, 4.803(s, 1H), 2.127-2.137(d, 6H). HRMS (ESI+): m/z: calcd for C27H18O5: 445.1046 [M+Na+]; found: 445.1098.

I c. 7-(4-chloromethyl-phenyl)-7H-pyrano[3,2-c;5,6-c'] dichromene-6,8-dione: $>300^{\circ} \mathrm{C}$. IR $\left(\mathrm{KBr}\right.$ pellet $\left.\mathrm{cm}^{-1}\right)$ : 3390, 2731, 1771, 1479, $1075 \mathrm{~cm}^{-1}$. 1H NMR (DMSO-d6, $\delta, \mathrm{ppm}):$ 8.405-8.428 (q, 2H), 7.757-7.800 (m, 2H), 7.506-7.578 (m, 4H), 7.403-7.424 (d, 2H), 7.329-7.350 (d, 2H), 4.899 (s, 1H), 4.701 (s, 2H). HRMS (ESI+): m/z: calcd for $\mathrm{C} 26 \mathrm{H} 15 \mathrm{ClO5}$ : $465.0500[\mathrm{M}+\mathrm{Na}+]$; found: 465.0564 .

l d. 7-(3,4-dichloro-phenyl)-7H-pyrano[3,2-c;5,6-c'] dichromene-6,8-dione: $>300^{\circ} \mathrm{C}$. IR $\left(\mathrm{KBr}\right.$ pellet $\left.\mathrm{cm}^{-1}\right)$ : $3329,2853,1799,1521,1120 \mathrm{~cm}^{-1}$. 1H NMR (DMSO$\mathrm{d} 6, \delta, \mathrm{ppm}): 8.398-8.421$ (q, 2H), 7.753-7.806 (m, 3H), 7.501-7.578 (m, 6H), $4.901(\mathrm{~s}, 1 \mathrm{H})$. HRMS (ESI+): m/ z: calcd for $\mathrm{C} 25 \mathrm{H} 12 \mathrm{Cl} 2 \mathrm{O} 5$ : $484.9954[\mathrm{M}+\mathrm{Na}+$ ]; found: 484.9919.

The synthesis method for compounds II (a-d) was similar to that of compounds I ( $a-d)$, in which Ac2O solvent was replaced by ethanol.

II a. 3,3'-((3,4,5-trimethoxyphenyl)methylene)bis (4-hydroxy-2H-chromen-2-one): $211-212^{\circ} \mathrm{C}$. IR $(\mathrm{KBr}$ pellet $\mathrm{cm}^{-1}$ ): 3066, 2672, 1912, 1654, $987 \mathrm{~cm}^{-1}$. 1H NMR (CDCl3, $\delta, \mathrm{ppm}): 11.586(\mathrm{~s}, 1 \mathrm{H}), 11.310(\mathrm{~s}, 1 \mathrm{H}), 8.048-8.092(\mathrm{~d}, 2 \mathrm{H})$, 7.641-7.684(m, 2H), 7.431-7.452(d, 4H), 6.441-6.443(d, 2H), 6.097(s, 1H), 3.873(s, 3H), 3.742(s, 6H). HRMS (ESI+): m/z: calcd for $\mathrm{C} 28 \mathrm{H} 22 \mathrm{O}$ : 525.1156 [M+Na+]; found: 525.1177.

I/ b. 3,3'-((4-(diethylamino)phenyl)methylene)bis(4hydroxy-2H-chromen-2-one): $221-222^{\circ} \mathrm{C}$. IR ( $\mathrm{KBr}$ pellet $\left.\mathrm{cm}^{-1}\right)$ :
$3411,2732,1878,1675,1219 \mathrm{~cm}^{-1}$. $1 \mathrm{H} \mathrm{NMR}$ (CDCl3, $\left.\delta, \mathrm{ppm}\right)$ : 8.033-8.061(m, 2H), 7.615-7.651(t, 2H), 7.379-7.432(q, 4H), 7.039-7.060(d, 2H), 6.634-6.655(d, 2H), 6.048(s, 1H), 3.3243.376(q, 4H), 1.145-1.180(t, 6H). HRMS (ESI+ ): m/z: calcd for C29H25NO6: 506.1574 [M+Na+]; found: 506.1519.

Il c. 3-(bis(4-hydroxy-2-oxo-2H-chromen-3-yl)methyl) benzonitrile: $242-243^{\circ} \mathrm{C}$. IR $\left(\mathrm{KBr}\right.$ pellet $\left.\mathrm{cm}^{-1}\right)$ : 3422 , 2754, 1910, 1678, $1029 \mathrm{~cm}^{-1}$. 1H NMR (CDCl3, $\left.\delta, \mathrm{ppm}\right)$ : $11.564(\mathrm{~s}, 1 \mathrm{H}), 11.353(\mathrm{~s}, 1 \mathrm{H}), 7.996-8.094(\mathrm{q}, 2 \mathrm{H}), 7.649-$ 7.688(t, 2H), 7.575-7.593(t, 1H), 7.390-7.507(m, 7H), 6.069(s, 1H). HRMS (ESI+): m/z: calcd for $\mathrm{C} 26 \mathrm{H} 15 \mathrm{NO} 6$ : $460.0792[\mathrm{M}+\mathrm{Na}+]$; found: 460.0766 .

II d. 3,3'-((4-chloro-3-(trifluoromethyl)phenyl)methylene) bis(4-hydroxy-2H-chromen-2-one): $219-220^{\circ} \mathrm{C}$. IR $(\mathrm{KBr}$ pellet $\mathrm{cm}^{-1}$ ): 3011, 2875, 2000, 1765, $1101 \mathrm{~cm}^{-1}$. $1 \mathrm{H}$ NMR (CDCl3, $\delta, \mathrm{ppm}): 11.568(\mathrm{~s}, 1 \mathrm{H}), 11.384(\mathrm{~s}, 1 \mathrm{H})$, 8.017-8.121 (q, 2H), 7.668-7.707 (t, 2H), 7.355-7.519 (m, $7 \mathrm{H}), 6.079$ (s, 1H). HRMS (ESI+): m/z: calcd for $\mathrm{C} 26 \mathrm{H} 14$ CIF3O6: 537.0323 [M+ Na+]; found: 537.0398 .

\section{Crystal structure determination}

According to the evaporation of chloroform solution, suitable single crystals of compound I b became available. The diffraction data were acquired on a Bruker Smart Apex CCD area detector using a graphite monochromated Mo K $\alpha$ radiation $(\lambda=0.71073 \AA$ ) at room temperature. The structure was solved by using the program SHELXL97 (20) and Fourier difference techniques, and refined by full-matrix least-squares method on F2. Hydrogen atoms attached to carbon were placed in geometrically idealized positions and refined using a riding model. 
Crystallographic data for compound I b are reported in Table 1.

Table 1. Crystal data and structure refinements for compound I b.

\begin{tabular}{|c|c|}
\hline Formula & $\mathrm{C} 27 \mathrm{H} 18 \mathrm{O} 5 \cdot \mathrm{CHCl} 3$ \\
\hline $\mathrm{Mr}$ & 541.78 \\
\hline Temperature/K & $293(2)$ \\
\hline Crystal system & Monoclinic \\
\hline Space group & $\mathrm{P} 21 / \mathrm{c}$ \\
\hline $\mathrm{a} / \AA$ & $15.1120(16)$ \\
\hline $\mathrm{b} / \AA \AA$ & $11.8560(12)$ \\
\hline$c / \AA ̊$ & $14.6020(14)$ \\
\hline$\alpha /^{\circ}$ & 90 \\
\hline$\beta /^{\circ}$ & $111.633(6)$ \\
\hline$\gamma /{ }^{\circ}$ & 90 \\
\hline VIÅ3 & $2431.9(4)$ \\
\hline Z & 4 \\
\hline Dcalc $/ \mathrm{g} \cdot \mathrm{cm}^{-3}$ & 1.480 \\
\hline$\mu($ Mo K $\alpha) / \mathrm{mm}^{-1}$ & 3.745 \\
\hline$\theta$ range $/^{\circ}$ & 3.15 to 72.74 \\
\hline Reflections collected & 26067 \\
\hline No. unique data $[R($ int $)]$ & $4754[0.0625]$ \\
\hline No. data with $I \geqslant 2 \sigma(I)$ & 4278 \\
\hline $\mathrm{R} 1$ & 0.0487 \\
\hline$\omega \mathrm{R} 2$ (all data) & 0.1182 \\
\hline
\end{tabular}

\section{Cytotoxicity assay}

The MTT (3-(4,5-dimethylthiazol-2-yl)-2,5-diphenyl-2Htetrazolium bromide) assay was performed as described previously (21). Cells were seeded onto a 96-well plate at a concentration of $10^{4}$ cells/well and allowed to adhere overnight. Five replicates were prepared for each treatment and cultured for 48 or $72 \mathrm{~h}$. After $20 \mu \mathrm{L}$ of MTT $(5 \mathrm{mg} / \mathrm{mL})$ was added to each well, the cells were cultured for another $4 \mathrm{~h}$. The supernatant was discarded. After $150 \mu \mathrm{L}$ of DMSO was added to each well, the samples were incubated at $37^{\circ} \mathrm{C}$ for $30 \mathrm{~min}$ and then swirled for $10 \mathrm{~min}$. The absorbance at $570 \mathrm{~nm}$ was measured using a microplate reader. Experiments were repeated three times.

\section{Results and Discussion}

\section{Molecular structure}

In order to confirm the configuration of the product, single crystals of compound I b were cultured for X-ray diffraction analysis. The crystal structure of compound I $\mathrm{b}$ is given in Figure 2. One can see a chloroform solvent molecule incorporated in the asymmetric unit. In general, the molecular dimensions of the title compound agree with the corresponding values of other similar compounds (9). In the title crystal structure, two 4-hydroxycoumarin moieties are linked through a methylene bridge, wherein

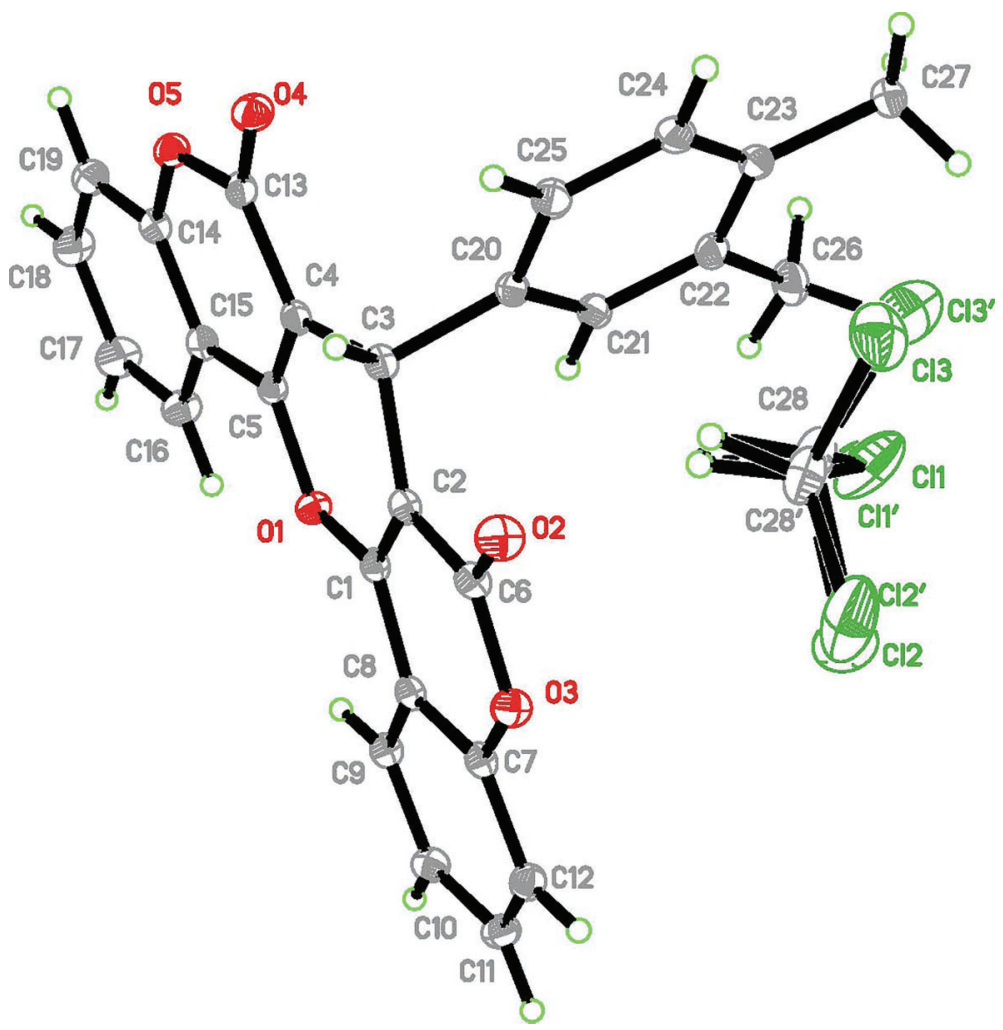

Figure 2. Molecular structure of compound I b. 


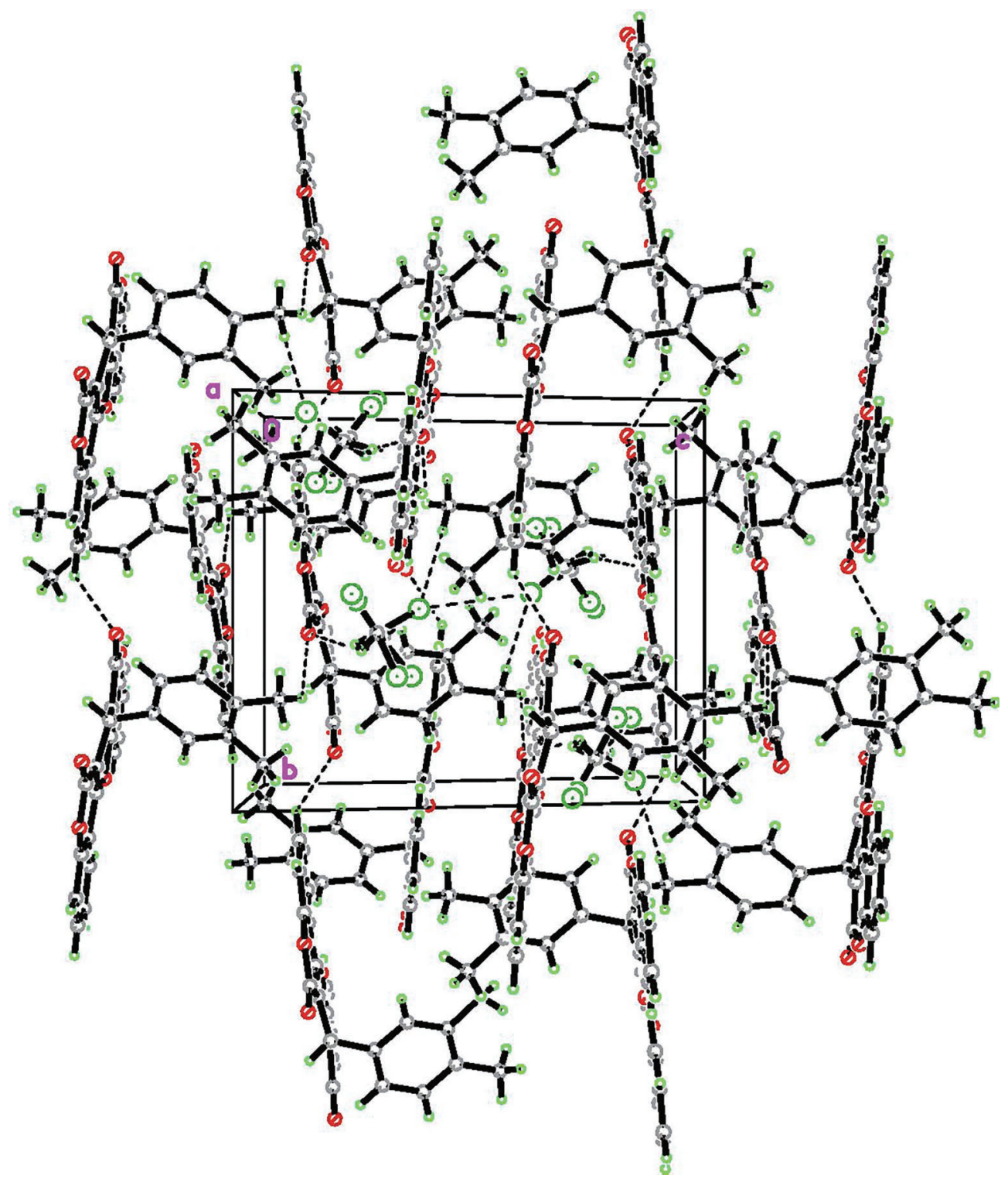

Figure 3. Crystal packing structure of compound I b along the a axis.

one hydrogen atom has been replaced with a 3,4dimethylphenyl residue. Two hydroxyl groups form an ether bond by releasing a water molecule. This results in the formation of a big, essential planar heterocyclic ring system with $4.349^{\circ}$ and $5.217^{\circ}$ dihedral angle between the newly formed ether ring and the two original coumarin rings, respectively. The dihedral angle between the mean planes of the heterocyclic ring system and the 3,4dimethylphenyl ring is $87.219^{\circ}$.

The crystal packing structure along the a axis is shown in Figure 3. Its crystal structure represents a threedimensional supra-molecular network. Within the threedimensional structure, there is one type of $\mathrm{C}-\mathrm{H} \ldots \mathrm{O}$; a hydrogen bonding is observed among these organic ligands. Detailed information of $\mathrm{C}-\mathrm{H}$... O hydrogen bonding is reported in Table 2. In other words, the threedimensional supra-molecular framework was generated by means of the $\mathrm{C}-\mathrm{H}$... O hydrogen bonding interactions.

\section{Pharmacology}

The synthesized compounds I $(a-d)$ and II $(a-d)$ were screened in vitro for their antitumor activities against SK-LU-1, SPC-A-1 and 95D human lung cancer cell lines using the standard MTT method, with the antitumor drug docetaxel used as a positive control. The in vitro cytotoxicity screening assays were conducted at different 
Table 2. Hydrogen bonds information (Angstrom, Deg).

\begin{tabular}{|c|c|c|c|c|c|}
\hline $\mathrm{D}-\mathrm{H} \ldots \mathrm{A}$ & $\mathrm{D}-\mathrm{H}$ & $\mathrm{H} \ldots \mathrm{A}$ & $D \ldots A$ & $\mathrm{D}-\mathrm{H} \ldots \mathrm{A}$ & Symmetry code \\
\hline C11-H11...O4 & 0.9500 & 2.5400 & 3.1714 & 124.00 & $x, 1+y, z$ \\
\hline C27-H27B ... O2 & 0.9800 & 2.5300 & 3.143 & 121.00 & $x, 1 / 2-y, 1 / 2+z$ \\
\hline C28-H28 ... O2 & 1.0000 & 2.1700 & 3.079 & 150.00 & \\
\hline
\end{tabular}

Table 3. In vitro anti-proliferative activity of I (a-d) and II (a-d) against human cancer cell lines.

\begin{tabular}{lrrr}
\hline Compounds & \multicolumn{3}{c}{ IC50 $(\mu \mathrm{M})$} \\
\cline { 2 - 4 } & SK-LU-1 & SPC-A-1 & 95D \\
\hline I a & $>100$ & $>100$ & $>100$ \\
I b & $>100$ & $>100$ & $>100$ \\
I c & 20 & 20 & 23 \\
I d & 25 & 25 & 21 \\
II a & 100 & $>100$ & $>100$ \\
II b & 100 & $>100$ & $>100$ \\
II c & 20 & 21 & 25 \\
II d & 22 & 20 & 23 \\
Doxorubicin & 25 & 30 & 25 \\
\hline
\end{tabular}

compound concentrations. All of the experiments were carried out in triplicate. The IC50 values were calculated

\section{References}

1. Wang W, Zhao Y, Rayburn ER, Hill DL, Wang H, Zhang R. In vitro anti-cancer activity and structure-activity relationships of natural products isolated from fruits of Panax ginseng. Cancer Chemoth Pharm 2007; 59: 589-601, doi: 10.1007/ s00280-006-0300-z.

2. Yi Y, Liao ST, Zhang MW, Zhang RF, Deng YY, Yang B, Wei ZC. Immunomodulatory activity of polysaccharide-protein complex of longan (Dimocarpus longan Lour.) pulp. Molecules 2011; 16: 10324-10336, doi: 10.3390/molecules161 210324.

3. Ting Min, Jie Sun, Yang Yi, Hong-Xun Wang, Fei Hang, You-Wei Ai, Li-Mei Wang. Microanalysis, Pharmacokinetics and Tissue Distribution of Polysaccharide-Protein Complexes from Longan Pulp in Mice. Int J Mol Sci 2015; 16: 24403-24416, doi: 10.3390/ijms161024403.

4. Zarranz B, Jaso A, Aldana I, Monge A. Synthesis and anticancer activity evaluation of new 2-alkylcarbonyl and 2-benzoyl-3-trifluoromethyl-quinoxaline 1,4-di-N-oxide derivatives. Bioorg Med Chem 2004; 12: 3711-3721, doi: 10.1016/ j.bmc.2004.04.013.

5. Smith NF, Figg WD, Sparreboom A. Recent advances in pharmacogenetic approaches to anticancer drug development. Drug Develop Res 2004; 62: 233-253, doi: 10.1002/ ddr.10361.

6. Sloan KB, Wasdo S. Designing for topical delivery: Prodrugs can make the difference. Med Res Rev 2003; 23: 763-793, doi: $10.1002 /$ med. 10048 . from the percentage of cytotoxicity by nonlinear curve fitting and are presented in Table 3.

Among all of the investigated compounds, I c, I d, II c and II $\mathrm{d}$ exhibited the most potent growth inhibition in the three lung cancer cells, with an IC50 value of $20-25 \mu \mathrm{M}$, indicating that they are more potent than docetaxel, which exhibited an IC50 value of $25-30 \mu \mathrm{M}$. In contrast, other compounds exhibited significantly weaker activity, because the cytotoxicity was lower than that of docetaxel in the three cell lines, with an IC50 value of $>100 \mu \mathrm{M}$.

In conclusion, among the coumarin compounds that we successfully synthesized, compounds I c, I d, II c and Il d had a strong electron-withdrawing group $(-\mathrm{CH} 2 \mathrm{Cl},-\mathrm{Cl}$, $-\mathrm{CN}$ and $-\mathrm{CF} 3$ ) in the phenyl ring with the highest cytotoxic activity against the cancer cell lines tested. Therefore, the four compounds are potential anticancer drugs, yet further tests are required to determine their in vivo antitumor activity.

7. Bao B, Ali S, Kong D, Sarkar SH, Wang Z, Banerjee S, et al. Anti-Tumor Activity of a Novel Compound-CDF Is Mediated by Regulating miR-21, miR-200, and PTEN in Pancreatic Cancer. PLOS One 2012; 6: e17850, doi: 10.1371/journal. pone.0017850.

8. Yu H, Huang Q. Enhanced in vitro anti-cancer activity of curcumin encapsulated in hydrophobically modified starch. Food Chem 2010; 119: 669-674, doi: 10.1016/j.foodchem. 2009.07.018.

9. Wang YC, Bachrach $U$. The specific anti-cancer activity of green tea (-)-epigallocatechin-3-gallate (EGCG). Amino Acids 2002; 22: 131-143, doi: 10.1007/s007260200002.

10. Li J, Xue X, Li X, Hou Z, Yang X, Qu D, et al. Synthesis of biscoumarin and dihydropyran derivatives as two novel classes of potential anti-bacterial derivatives. Arch Pharm Res 2016; 39: 1349-1355, doi: 10.1007/s12272-015-0614-7.

11. Li J, Sui YP, Xin JJ, Du XL, Li JT, Huo HR, et al. Synthesis of biscoumarin and dihydropyran derivatives with promising antitumor and antibacterial activities. Bioorg Med Chem Lett 2005; 25: 5520-5523, doi: 10.1016/j.bmcl.2015.10.063.

12. Nofal ZM, Elzahar MI, Elkarim SSA. Novel Coumarin Derivatives with Expected Biological Activity. Molecules 2000; 5: 99-113, doi: 10.3390/50200099.

13. Luo K, Wu F, Zhang D, Dong R, Fan Z, Zhang R, Yan Z, Wang Y, Zhang J. Transcriptomic profiling of Melilotus albus near-isogenic lines contrasting forcoumarin content. Sci Rep 2017; 7: 4577, doi: 10.1038/s41598-017-04111-y. 
14. Chen LZ, Sun WW, Bo L, Wang JQ, Xiu C, Tang WJ, Shi JB, Zhou HP, Liu XH. New arylpyrazoline-coumarins: Synthesis and anti-inflammatory activity. Eur J Med Chem 2017; 138: 170-181, doi: 10.1016/j.ejmech.2017.06.044.

15. Kontogiorgis CA, Hadjipavlou-Litina DJ. Synthesis and antiinflammatory activity of coumarin derivatives. J Med Chem 2005; 48: 6400-6408, doi: 10.1021/jm0580149.

16. Lee S, Sivakumar K, Shin WS, Xie F, Wang Q. Synthesis and anti-angiogenesis activity of coumarin derivatives. Bioorg Med Chem Lett 2006; 37: 4596-4599, doi: 10.1002/ chin.200651115.

17. Li J, Lv CW, Li XJ, Qu D, Hou Z, Jia M, et al. Synthesis of biscoumarin and dihydropyran derivatives and evaluation of their antibacterial activity. Molecules 2015; 20: 17469-17482, doi: 10.3390/molecules200917469.
18. Tan S, He F, Kong T, Wu J, Liu Z. Design, synthesis and tumor cell growth inhibitory activity of 3-nitro-2H-cheromene derivatives as histone deacetylaes inhibitors. Bioorg Med Chem 2017; 25: 4123-4132, doi: 10.1016/j.bmc.2017. 05.062.

19. Yamaguchi $\mathrm{Y}$, Nishizono N, Kobayashi D, Yoshimura T, Wada K, Oda K. Evaluation of synthesized coumarin derivatives on aromatase inhibitory activity. Bioorg Med Chem Lett 2017; 27: 2645-2649, doi: 10.1016/j.bmcl.2017.01.062.

20. Sheldrick GM. SHELXL-97, program for solution crystal structure and refinement. Götingen: University of Götingen; 1997.

21. Kupcsik L. Estimation of cell number based on metabolic activity: the MTT reduction assay. Methods Mol Biol 2011; 740: 13-19, doi: 10.1007/978-1-61779-108-6_3. 